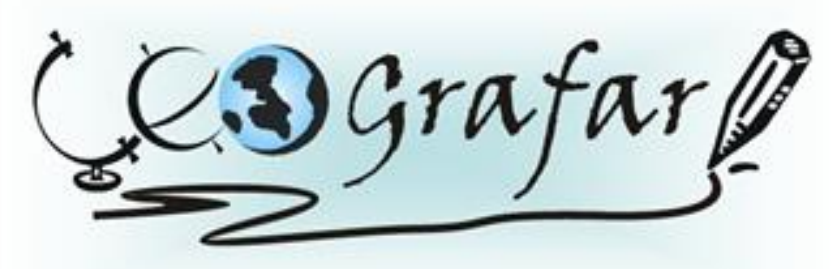

Revista Eletrônica do Programa de Pós-Graduação em Geografla - UFPR

\title{
A GESTÃO DOS RECURSOS NATURAIS NA AMAZÔNIA: A RESERVA EXTRATIVISTA MÃE GRANDE DE CURUÇÁ-PA.
}

\author{
CHARLES BENEDITO GEMAQUE SOUZA ${ }^{1}$
}

\begin{abstract}
Resumo: A perspectiva da sustentabilidade surge como uma possibilidade de inclusão daqueles que historicamente ficaram á margem dos planos implantados na Amazônia. Nesse contexto, a gestão dos recursos naturais na região está sendo delineada a partir da criação de diversos modelos de Unidades de Conservação, tendo nas Reservas Extrativistas (RESEX) um instrumento inovador de garantia de direitos constitucionais sobre o meio ambiente. Com base nesses pressupostos, a pesquisa de campo foi realizada na Reserva Extrativista Marinha Mãe Grande de Curuçá-PA, a partir de entrevistas semi-estruturadas e a observação direta. Cujo objetivo central é analisar as particularidades de uma experiência de desenvolvimento sustentável criada a partir da mobilização e luta de comunidades que ainda sobrevivem do extrativismo e da pesca artesanal em contraposição a lógica capitalista de crescimento econômico e de modernização do espaço.
\end{abstract}

Palavras-Chave: RESEX; Extrativismo; Sustentabilidade.

\section{THE MANAGEMENT OF NATURAL RESOURCES IN THE AMAZON THE RESERVE EXTRACTIVISTE MÃE GRANDE OF CURUÇÁ-PA.}

\begin{abstract}
The perspective of the sustainable development appears as an inclusion possibility of those that historically were apart from the plans implanted in the Amazon. In that context, the management of the natural resources in the area is being delineated starting from the creation of several models of Conservation Units, proposing in the Extractiviste Reserve (RESEX) an innovative instrument of warranty of constitutional rights on the environment. Based on those presuppositions, the field research was accomplished in the Extractiviste Marine Reserve Mãe Grande of Curuçá-PA, starting with semi-structured interviews and the direct observation. The main goal was to analyze the particularities of an experience of sustainable development coming from the mobilization and communities' fight that still survive of the extrativism and of the handmade fishing in opposition the capitalist logic of economical growth and of modernization of the space.
\end{abstract}

Key words: RESEX, Extrativistes, Sustainable.

\footnotetext{
${ }^{1}$ Geógrafo. Doutorando em Desenvolvimento Sustentável do Tropico Úmido do Núcleo de Altos Estudos Amazônicos da Universidade Federal do Pará. NAEA/UFPA.
} 


\section{INTRODUÇÃO}

Curuçá é um município que se notabiliza pela comercialização de peixes e mariscos, tornando-se um tradicional e importante centro pesqueiro do Nordeste paraense. O núcleo urbano tem sua orla voltada para o rio Curuçá, criando um espaço geográfico típico das localidades ribeirinhas da Amazônia, enriquecido por porções litorâneas ocupadas por manguezais.

De outro lado, existem comunidades no município que exercem outras praticas como o extrativismo tradicional e agricultura familiar exercendo a pesca e a coleta de caranguejo e camarão apenas como uma atividade complementar. Destaca-se também a atividade turística, embora seja marcada pelo caráter sazonal e espontâneo, como indica a principal manifestação cultural do município: o bloco carnavalesco conhecido regionalmente como os "Pretinhos do Mangue".

Contudo, a partir da criação da Reserva Extrativista (RESEX) Marinha Mãe Grande de Curuçá iniciou-se uma serie de controvérsias sobre a sustentabilidade ambiental e socioeconômica desse tipo de gestão dos recursos naturais na região. Tal discussão passa por diversas interpretações, entre as quais algumas apontam não apenas a insustentabilidade econômica, mas o próprio fim da atividade extrativa na Amazônia (HOMMA, 1992; AMIN, 1997). Outras designam um fortalecimento da atividade extrativista por meio de mudanças no âmbito das relações ecológicas, e da valorização socioeconômica das praticas sustentáveis (ALLEGRETTI, 1994a).

Trata-se aqui de analisar a construção social da Reserva Extrativista Marinha Mãe Grande por meio dos impactos sobre Curuçá tanto em termos de sustentabilidade dos recursos naturais como da dinâmica produtiva para o desenvolvimento do município. $O$ intuito é observar como as atividades tradicionais como a pescaria e extrativista adaptaram-se as outras relações de produtividade econômica e de trabalho, e como essas transformações são vistas no âmbito das interações homem/natureza, através da gestão da biodiversidade.

Para tanto, o estudo teve como base metodológica a observação de campo sistemático, consubstanciado pelo debate entre as principais correntes teóricas sobre o tema e a contextualização das RESEX na região. Nesse contexto, o 
encontro com os interlocutores no próprio município de Curuçá foi um instrumento fundamental de sistematização dessa pesquisa, principalmente para obter os elementos verbais não formalizados em documentos oficiais e acadêmicos. Contribuindo, desta forma, com aspectos da percepção geográfica para a questão da sustentabilidade do modelo da RESEX para o desenvolvimento da Amazônia.

\section{O EXTRATIVISMO FACE À RACIONALIDADE CAPITALISTA NA AMAZÔNIA}

Dentre as atividades produtivas implementadas ao longo dos anos na Amazônia, aquela que causou menores impactos ambientais e sociais, pelos menos a priori, seria o extrativismo de base tradicional, conquanto existem duvidas sobre a viabilidade do extrativismo como vetor de um desenvolvimento econômico e suas implicações para o futuro da região.

Nesta perspectiva, existem duas interpretações aparentemente divergentes, a primeira defendida por autores como Allegretti (1994a) atribui ao parâmetro extrativista o ideário de sustentabilidade para a Amazônia, em todas as suas dimensões, enquanto para outros, como Homma (1989), enxergam nesse modelo uma acomodação eterna da região ao subdesenvolvimento. Neste contexto, é necessário evidenciar cada uma dessas vertentes que polarizam essa discussão para uma posterior reflexão inicial e sucinta sobre a viabilidade ou não do extrativismo.

Conforme a abordagem de Homma (1989) com a expansão da fronteira e o crescimento populacional houve um processo de esgotamento/estagnação da atividade extrativista vegetal na Amazônia. De outro lado, fatores endógenos e exógenos revestem-se como de fundamental relevância a conservação e utilização racional dos recursos naturais.

Diante desses pressupostos, a questão é que tanto para fazer a preservação quanto o desmatamento é necessário haver a concordância da sociedade em geral. O problema é que o extrativismo vegetal embora seja uma atividade que abarque um contingente expressivo de pessoas na região, constitui-se em uma base de 
desenvolvimento frágil, que se justifica mais pelo nível de pobreza, cuja tendência é o seu desaparecimento à medida que a economia de mercado for sendo implantado para esses produtos extraídos.

Para exemplificar Homma (1994) cita a "estratégia do índio", que sempre foi considerado um modelo de convívio com a natureza, porém no momento do contato com outras culturas esse modelo tende a desagregar. Desta forma, o autor considera uma "irracionalidade" apostar que uma sustentabilidade (ambiental, econômica e social) micro e ligada diretamente a um determinado grupo social possam dar estabilidade para toda uma região com diversos interesses em jogo.

Neste caso, o mesmo autor (1992) aponta que o extrativismo como modelo de desenvolvimento serviria mais para agradar uma comunidade ecológica internacional do que uma opção viável de crescimento econômico. Mesmo porque a falta de interesse dos investidores internos e o desconhecimento dos externos obrigam ao Estado criar toda uma política de investimentos, controle e de benefícios sociais.

Outro ponto questionado pelo autor é que uma possível proliferação de uma política de controle criaria um suposto ambiente artificialmente isolado e de restrição à liberdade duramente conquistada. A questão para ele é que o interesse dos grupos tradicionais nas reservas decorre muito mais pela falta de infra-estrutura educacional, saneamento, saúde do que interesses ecológicos, a presença do Estado parece ser o objetivo final.

Evidentemente, a tese defendida por esse autor e seus seguidores tem fundamento, todavia esse viés interpretativo também tem falhas, notadamente no caráter simplista com que aborda o extrativismo vegetal na Amazônia. De acordo com Rego (1999) o conceito que serve de base de interpretação restringe-se a coleta de produtos naturais com produtividade baixa, porém existem atividades de manejo, beneficiamento que mesmo dentro de contexto social extrativista, já são um processo de domesticação desses produtos.

Neste contexto, o denominado neo-extrativismo introduz uma produção extrativista de cultivos, criações e beneficiamento, cada vez mais praticado por produtores autônomos e organizados e dentro de valores próprios dessa sociedade. 
Em outras palavras, na Amazônia a evolução da atividade extrativista também pressupõe um conhecimento empírico capaz de orientar o projeto de manejo.

Assim, o problema de viabilidade econômica da atividade extrativista representa na verdade um pensamento economicista, ligado ao avanço tecnológico. Conforme Rego (1999) que esta por trás desse (pré) conceito sobre o extrativismo em geral é uma racionalidade instrumental e neoclássica que valoriza apenas o âmbito econômico. A questão é que precisamos levar em consideração a todas as instâncias da vida social: econômico, política, cultural e ambiental.

Já Allegretti (1994b) parte da idéia que o uso dos recursos naturais renováveis precisa ser projetado através de uma adequada distribuição das riquezas produzidas e para as políticas de uso restritivo desses recursos. Entre as diversas alternativas que se apresentam para a Amazônia, a autora indica a idéia de reserva extrativista (Resex) como a única que proporciona uma conciliação entre os interesses de conservação do meio ambiente e o desenvolvimento social.

Todavia, o extrativismo, historicamente, tornou-se uma noção vinculada ao tradicionalismo, uma herança das antigas atividades produtivas condenada a desaparecer. Para Allegretti (1994a) o termo extrativismo carrega o peso do "convencional", de uma etapa da humanidade a muito deixado de lado no processo de desenvolvimento da humanidade. Em outras palavras, a extração convencional dos recursos naturais é uma atividade que supostamente precedia agricultura e a industrialização na evolução produtiva.

Por outro lado, o extrativismo de maneira geral abarcaria uma das formas mais primitivas e injustas de sistema de trabalho: o aviamento. Trata-se de uma relação baseada na troca da força de trabalho por mercadorias que cria um endividamento incontrolável. Diante dessa interpretação, o extrativismo é considerado inadequado por diversos autores que trabalham na região (BUNKER 1985), e totalmente extemporâneo não apenas do contexto econômico vigente, mas das relações sociais e das preocupações ambientais.

Para rebater essas criticas, Allegretti (1994a) chama atenção que é preciso reconhecer primeiro que existem populações tradicionais na região amazônica que utilizam o extrativismo como meio produtivo de subsistência, e em segundo lugar a 
inexistência de alternativas econômicas e sociais que contemplem de fato a especificidade destes grupos sociais. Logo, é nessa perspectiva que atividade extrativista não pode ser descartada sob pena de segregar uma parcela considerável dessas famílias que realmente vivem na região.

Ademais, a autora revela que é necessário esclarecer que apesar da denominação enfatizar o extrativismo, existe áreas e atividades para qual o conceito é comumente utilizado que na realidade são produtividades ligadas a agricultura, pesca e a atividades ligadas ao manguezal (ALEGRETTI, 1994a, p. 19). Em conseqüência a base produtiva extrativista acaba não se resumindo ao extrativismo vegetal convencional.

A base extrativista sugerido pela autora quer assegurar uma nova racionalidade de ocupação (proteção) dessas áreas, trata-se inicialmente de estabelecer uma condição: a sustentabilidade ambiental e social. Isto não significa que o aspecto econômico não esteja inserido no processo, logo é preciso políticas de incentivos fiscais, ao mesmo tempo em que se devem criar barreiras de proteção e formas de escoamento das mercadorias produzidas.

Deste modo, o grande diferencial é que o controle do uso do recurso natural, assim como da gestão, estaria nas mãos dos extrativistas, agregando valor aos produtos da floresta a partir do controle da cadeia produtiva. Para Allegretti (1994a) isto se constitui em um marco inicial de novo modelo econômico para a Amazônia, que tem como base critérios como a conservação ambiental e a equidade social. $O$ que "representa uma mudança no quadro de exploração social em que vivem as populações extrativistas da nossa região".

Por ultimo, a autora evidencia que se não houver pesquisas e acréscimo tecnológico, assim como políticas de insumos, e nem um aperfeiçoamento do modelo fica difícil o êxito na conciliação entre o desenvolvimento social e econômico e a conservação. Contudo, Allegretti (1994b) nos lembra que as politicas de conservação ambiental já prestam um grande serviço quando sua existência, única e exclusivamente significa uma diminuição do desmatamento, mesmo que esta seja de forma isolada e equivocada. 
Em síntese, é possível afirmar que Homma e Alegretti chegam a conclusões convergentes: o extrativismo só é viável como modelo de desenvolvimento para a Amazônia, caso modifique-se, incorporando novas práticas, ou seja, o extrativismo "puro" é inviável. Trata-se de incrementar uma atividade extrativista que se insira na economia do mercado sem entrar em conflito com o modo de vida local, o que implica respeitar o ambiente e a cultura pré-existentes. Evidentemente, tal simbiose não é facilmente factível em uma região cujos interesses são diversos e historicamente conflitantes.

\section{A EVOLUÇÃO HISTÓRICA DAS RESEX’S NA AMAZÔNIA}

A participação das atividades extrativistas na economia da Amazônia é significativa, na região são extraídos 80 \% da produção nacional de madeiras, por sua vez a mineração é responsável por uma nova frente econômica na região. Enquanto a extração vegetal apesar de pouco atrativo economicamente, se comparado com as outras praticas extrativistas, continua prevalecendo pela abundancia e pelos custos.

Infelizmente existem, ainda hoje, grandes empecilhos à maior produção de produtos de extração convencional, apesar de comprovadamente ter um grande potencial na Amazônia. Neste contexto, as primeiras Reservas extrativistas (Resex) foram criadas a partir de 1990 criando, assim, um território legal de conservação e utilização dos recursos florestais e de sustentabilidade ambiental das atividades produtivas na Amazônia.

As Unidades de conservação (UC) surgem inicialmente baseadas em ilhas estratégicas de conservação de biodiversidade, de uso indireto. Com a crescente inquietação ambientalista mundial aliado ao crescente movimentos sociais, em especial do seringueiro, excluídas do processo de desenvolvimento, ganham destaque as UC's de uso direto, em particular as RESEX's que surgiram como uma alternativa para atenuar o problema fundiário de concentração de terra, promover a exploração dos recursos naturais de forma sustentável e de conservar a biodiversidade no território amazônico (Allegretti, 1989). 
Ainda conforme Allegretti (1994a) o fundamental da proposta da Resex é que foi formulado por aqueles que conhecem e vivem na região: os seringueiros, portanto, não é uma estratégia criada em gabinete para beneficiar o "povo". Pelo contrario, é uma resposta desses grupos sociais excluídos a uma situação histórica extremamente desfavorável, e que pode ser transbordada para outros grupos regionais que vivem a mesma situação.

Com isso, a concepção de Reserva extrativista remete a idéia de domínio publico o que estar amarrado a uma concessão real de uso do território destinado à conservação ambiental e de modos de vida, outorgada, assim, à comunidade e não individualmente (CHAMY, 2008). Neste aspecto, a comunidade local, com a fiscalização do IBAMA, é responsável direto pelo gerenciamento dos recursos naturais por meio de um plano de manejo, o que deveria representar menos burocracia e ganhos para todos os envolvidos.

Ao mesmo tempo, a proposta de criação de Resex passa a ser aceito como um plano de Reforma Agrária para os extrativistas, visto que um dos escopos era legitimar a posse e de reconhecer os direitos à terra daqueles que nela trabalhavam durante anos. Diante disso, o INCRA elaborou uma portaria de numero 627 de 30/07/1987 que criou o Projeto de Assentamento Extrativista (PAE), destinando áreas de assentamentos para populações extrativistas, mediante concessão de uso de regime comunal e sustentável.

Atualmente existem 22 Resex cadastradas na Amazônia legal (Quadro 1), incluindo as Reservas extrativistas marinhas, afetando mais de 30000 pessoas e quase 4 milhões de hectares da Região, enquanto a maioria dos extrativistas em geral, que não estão em reservas, ocupa uma área muito maior. Entre as atividades desenvolvidas destaca-se a extração da borracha, babaçu, da castanha e do açaí, além da pesca artesanal e a mariscagem. 


\section{QUADRO 1: RESERVAS EXTRATIVISTAS NA AMAZÔNIA LEGAL}

\begin{tabular}{|c|c|c|c|c|c|c|}
\hline Nome da Resex & Estado & Município & Decreto & $\begin{array}{l}\text { Área } \\
(\mathrm{Ha})\end{array}$ & $\begin{array}{l}\text { Popul } \\
\text { ação }\end{array}$ & Recursos Naturais \\
\hline Alto Juruá & $A C$ & $\begin{array}{c}\text { Thaumaturgo de } \\
\text { Azevedo }\end{array}$ & $\begin{array}{l}98.863- \\
23 / 01 / 90\end{array}$ & $\begin{array}{c}506.18 \\
\quad 6\end{array}$ & 3.600 & Borracha \\
\hline Chico Mendes & $\mathrm{AC}$ & $\begin{array}{c}\text { Rio Branco / } \\
\text { Xapuri / Brasiléia } \\
\text { / Assis } \\
\text { Brasil / Sena } \\
\text { Madureira / } \\
\text { Capixaba }\end{array}$ & $\begin{array}{l}99.144- \\
12 / 03 / 90\end{array}$ & $\begin{array}{c}970.57 \\
0\end{array}$ & 7.500 & $\begin{array}{c}\text { Castanha / Copaíba } \\
\text { /Borracha }\end{array}$ \\
\hline Alto Tarauacá & $A C$ & $\begin{array}{l}\text { Jordão e } \\
\text { Tarauacá }\end{array}$ & $\begin{array}{c}S / N^{\circ}- \\
08 / 11 / 00\end{array}$ & $\begin{array}{c}151.19 \\
9\end{array}$ & 724 & Borracha \\
\hline Rio Cajarí & AP & $\begin{array}{l}\text { Laranjal do Jarí / } \\
\text { Mazagão / } \\
\text { Vitória do Jarí }\end{array}$ & $\begin{array}{l}99.145- \\
12 / 03 / 90\end{array}$ & $\begin{array}{c}481.65 \\
0\end{array}$ & 3.800 & $\begin{array}{c}\text { Castanha / Copaíba } \\
\text { / } \\
\text { Borracha / Açaí }\end{array}$ \\
\hline Rio Ouro Preto & $\mathrm{RO}$ & $\begin{array}{l}\text { Guajará-Mirim / } \\
\text { Nova Mamoré }\end{array}$ & $\begin{array}{l}99.166- \\
13 / 03 / 90\end{array}$ & $\begin{array}{c}204.58 \\
3\end{array}$ & 700 & $\begin{array}{c}\text { Castanha / Copaíba } \\
/ \\
\text { Borracha }\end{array}$ \\
\hline Barreiro das Antas & RO & Guajará-Mirim & $\begin{array}{c}S / N^{\circ}- \\
07 / 08 / 01\end{array}$ & $\begin{array}{c}107.23 \\
4\end{array}$ & 400 & Borracha \\
\hline Rio Cautário & RO & Guajará-Mirim & $\begin{array}{c}S / N^{\circ}- \\
07 / 08 / 01\end{array}$ & 73.817 & 300 & Borracha \\
\hline Lago do Cuniã & RO & Porto Velho & $\begin{array}{c}3238- \\
10 / 11 / 99\end{array}$ & 52.065 & 290 & Pescado \\
\hline Extremo Norte do TO & TO & Carrasco Bonito & $\begin{array}{c}535- \\
20 / 05 / 92\end{array}$ & 9.280 & 800 & Babaçú / Pescado \\
\hline Mata Grande & MA & $\begin{array}{l}\text { Senador La } \\
\text { Rocque }\end{array}$ & $\begin{array}{c}532- \\
20 / 05 / 92\end{array}$ & 10.450 & 500 & Babaçú / Pescado \\
\hline Quilombo do Frexal & MA & Mirinzal & $\begin{array}{c}536- \\
20 / 05 / 92\end{array}$ & 9.542 & 900 & Babaçú / Pescado \\
\hline
\end{tabular}




\begin{tabular}{|c|c|c|c|c|c|c|}
\hline Ciriáco & MA & Cidelândia & $\begin{array}{c}534- \\
20 / 05 / 92\end{array}$ & 7.050 & 1.150 & Babaçú \\
\hline Tapajós-Arapiuns & PA & $\begin{array}{l}\text { Santarém / } \\
\text { Aveiro }\end{array}$ & $\begin{array}{c}S / N^{\circ}- \\
06 / 11 / 98\end{array}$ & $\begin{array}{c}647.61 \\
0\end{array}$ & 4.000 & $\begin{array}{c}\text { Borracha / Pesca / } \\
\text { Óleos } \\
\text { e Resinas }\end{array}$ \\
\hline Auati-Paraná & AM & Fonte Boa & $\begin{array}{c}\mathrm{S} / \mathrm{N}^{\circ}- \\
07 / 08 / 01\end{array}$ & $\begin{array}{c}146.95 \\
0\end{array}$ & 1.246 & Borracha \\
\hline Baixo Juruá & AM & Juruá / Uarini & $\begin{array}{c}\mathrm{S} / \mathrm{N}^{\circ}- \\
01 / 08 / 01\end{array}$ & $\begin{array}{c}187.98 \\
2\end{array}$ & 1.050 & Borracha \\
\hline Médio Juruá & AM & Carauari & $\begin{array}{c}\mathrm{S} / \mathrm{N}^{\circ}- \\
04 / 03 / 97\end{array}$ & $\begin{array}{c}253.22 \\
6\end{array}$ & 700 & Borracha / Pesca \\
\hline Rio Jutaí & AM & Jutaí & $\begin{array}{c}\mathrm{S} / \mathrm{N}^{\circ}- \\
16 / 07 / 02\end{array}$ & $\begin{array}{c}275.53 \\
3\end{array}$ & 500 & $\begin{array}{c}\text { Borracha, óleos e } \\
\text { Pescado }\end{array}$ \\
\hline Cazumbá - Iracema & $A C$ & $\begin{array}{l}\text { Sena Madureira / } \\
\text { Manoel Urbano }\end{array}$ & $\begin{array}{c}\mathrm{S}^{\prime} \mathrm{N}^{\circ}- \\
19 / 09 / 02\end{array}$ & $\begin{array}{c}750.79 \\
4\end{array}$ & 754 & $\begin{array}{c}\text { Borracha/Castanh } \\
\text { a }\end{array}$ \\
\hline Soure* & $\mathrm{PA}$ & Soure & $\begin{array}{c}\text { S/No - } \\
\text { 22/11/01 }\end{array}$ & 27.463 & 1400 & $\begin{array}{l}\text { Pescado e } \\
\text { Crustáceos }\end{array}$ \\
\hline Maracanã ${ }^{*}$ & $\mathrm{PA}$ & Maracanã & $\begin{array}{c}\text { S/No - } \\
\text { 13/12/02 }\end{array}$ & $\begin{array}{c}30.018 \\
, 88\end{array}$ & $s / n$ & $\begin{array}{c}\text { Manguezais e } \\
\text { pesca } \\
\text { Artesanal }\end{array}$ \\
\hline Chocoaré* $^{*}$ & PA & Santarém Novo & $\begin{array}{c}\text { S/NNo - } \\
\text { 13/12/02 }\end{array}$ & $\begin{array}{c}2.785 \\
72\end{array}$ & 2.785 & $\begin{array}{c}\text { Manguezais e } \\
\text { pesca } \\
\text { Artesanal }\end{array}$ \\
\hline $\begin{array}{l}\text { Mãe Grande de } \\
\text { Curuçá* }\end{array}$ & PA & Curuçá & $\begin{array}{c}\text { S/NNo - } \\
\text { 13/12/02 }\end{array}$ & $\begin{array}{c}37.064 \\
, 23\end{array}$ & 6000 & $\begin{array}{c}\text { Manguezais e } \\
\text { pesca } \\
\text { artesanal }\end{array}$ \\
\hline
\end{tabular}

Fonte: IBAMA/CNPT

${ }^{*}$ Reservas Extrativistas Marinhas

A Reserva extrativista do Alto Juruá, no município de Thaumaturgo de Azevedo no Acre foi a primeira a ter o seu decreto de criação (98.863) aprovado em 23 de Janeiro de 1990. Na mesma época foi criada a Resex Chico Mendes também no Acre, a maior reserva em extensão como mais de 970500 ha de área legal, o que 
abrange seis municípios do Estado, e com uma população em torno de 7500 habitantes em sua maioria seringueiros.

Em 1992, foi criada a primeira Resex fora do limite da Amazônia e distinta em relação aos recursos naturais a serem geridos pela comunidade local, trata-se da Reserva extrativista marinha de Pirajubaé em Santa Catarina. Edifica-se uma subcategoria das Resex's identificado com os territórios marinhos, o que aumentou o numero de pedidos para a delimitação de espaços secularmente ocupados por pescadores artesanais, um indício de fortalecimento e amadurecimento na organização e mobilização social de uma parcela populacional historicamente marginalizada (CHAMY, 2008).

Em 1997 foi decretada a criação da Resex do Médio Juruá no município de Carauari no Amazonas, a primeira em que os recursos naturais são totalmente atrelados as áreas marinhas na região. Apesar da presença significativa de seringueiros na Amazônia, a viabilidade da idéia de "extrativismo" em outros ambientes demonstra ser possível e recomendável, mesmo porque, a pesca artesanal é uma característica forte do modo de vida amazônico, principalmente daqueles que vivem as margens de igarapés e rios da região, os denominados povos ribeirinhos.

No entanto, somente em 2002, surgem oficialmente as Reservas Extrativistas Marinhas na Amazônia, mais especificamente no Estado do Pará, delimitando territórios de uso exclusivo dos grupos de pescadores artesanais locais. Entretanto, segundo Chamy (2008) nas Resex marinhas a exclusão dos não comunitários e a falta de gerenciamento de áreas de exploração de outros recursos naturais podem levar a conflitos nas áreas do entorno, o enfraquecimento na manutenção das atividades destas populações e a exclusão por setores economicamente mais fortes como a pesca industrial, o turismo e a especulação imobiliária.

Em resumo, após 18 anos as Reservas extrativistas da Amazônia ainda têm o desafio de superar o atraso nos instrumentos de produção, fiscalização, gerenciamento e de comercialização dos recursos naturais que acarretam um desempenho inferior em relação às outras atividades produtivas implantadas na 
região. Contudo, trata-se ainda da alternativa mais viável de sustentabilidade ambiental, econômica e cultural das comunidades mais tradicionais da Amazônia.

\section{A PRODUÇÃO DO ESPAÇO MUNICIPAL FACE À CONSTRUÇÃO SOCIAL DA RESEX MẤE GRANDE}

Curuçá foi criado em 14 de maio de 1895 e está localizado na mesorregião do nordeste paraense, na microrregião do salgado. Os seus limites são o oceano atlântico ao norte, o município de Castanhal ao sul, a leste com o município de Marapanim e a oeste com o município de São Caetano de Odivelas. Para o IBGE a população estimada da cidade de Curuçá no ano de 2006 é de 30343 mil pessoas e seu produto interno bruto seria entorno de 54000 R (IBGE, 2007).

O nome Curuçá tem origem indígena o termo "curu" que significa seixos e cascalhos e "ça" (ou melhor çaba) que quer dizer em que, logo o significado deste topônimo seria o "lugar em que há seixos e cascalhos" (FERREIRA, 2006). A sua fundação data das antigas reduções dos jesuítas, no século XVII, quando instalaram uma fazenda que denominaram de Curuçá, às margens do rio do mesmo nome, onde existia uma importante feitoria de pesca. Atualmente o Município de Curuçá está integrado pelos distritos de Curuçá (sede), Lauro Sodré, Murajá e Ponta de Ramos. 


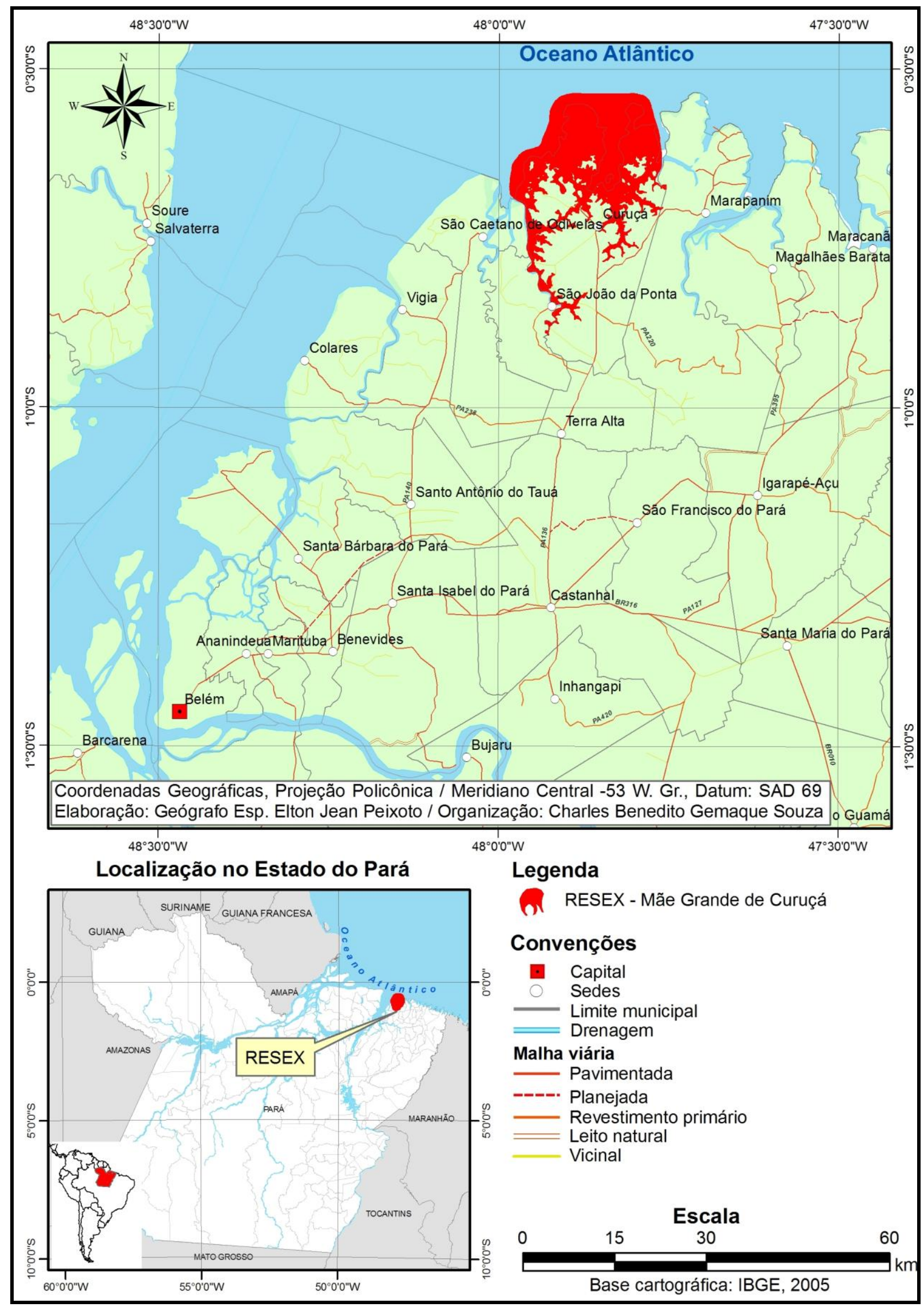


O rio Mocajuba é um dos mais importantes rios no Município, formado pelo Igarapé Pimenta e outros tributários sem grande expressão, servindo de limite natural a Oeste separando os Municípios de São João da Ponta e São Caetano de Odivelas do Município de Curuçá, corre em direção a Sudeste-Noroeste formando meandros, para depois toma a direção norte, desaguando no Oceano Atlântico. Recebe vários afluentes, sendo os da margem direita os de maior importância, para o Município.O rio Curuçá é o segundo mais expressivo do Município, sendo que, no seu afluente, rio Baunilha, pela margem esquerda, se encontra a sede municipal.

A população local é de habito simples, contudo suscetível a qualquer transformação engendrada pelo consumismo e competitividade da racionalidade moderna. Nesse contexto, o município de Curuçá assemelha-se ao espaço vivido em diversas localidades ribeirinhas da Amazônia, na qual as relações são produtos de um cotidiano marcado pela apropriação da natureza pelo homem, principalmente o rio. De acordo com Figueiredo (2007) quando é criada qualquer perturbação nessa apropriação, provoca alterações irreversíveis na estabilidade dos recursos naturais, e conseqüentemente nas relações sociais.

Em termos econômicos, as principais atividades são a pesca artesanal e a mariscagem, no entanto o sistema de agricultura itinerante vem sendo utilizado para produção de subsistência. De acordo com Galdino (2007) é freqüente a incidência de queimadas no município, devido à falta de informação, as épocas de secas prolongadas e a ausência de aceiros ao queimar. Por fim, o extrativismo continua bastante tradicional, embora existam casos de uso de insumos químicos, fertilizantes e defensivos, porém, com pouca mecanização das técnicas.

Existem relatos que revelam que chegam todos os dias ao porto do Abade, a colônia de pescadores do município, caminhões frigoríficos que compram grandes quantidades do pescado, restando para consumo dos habitantes locais, os peixes que são pouco valorizados para comercialização (TORRES, 2004). Não existem dados oficiais acerca do volume da produção, tampouco do numero exato de seus associados. Estimam que apenas cerca de 500 pescadores paguem regularmente a associação, entre 2.000 inscritos. 
Há arranjos formais e informais que são adotados no sentido de estabelecer mecanismos que permitem disciplinar as inter-relações necessárias à continuidade das atividades pesqueiras. Como exemplo, foi construído pelo governo do estado o mercado municipal da vila do Abade, com o intuito de criar um local mais adequado para a comercialização de peixes e mariscos do município.

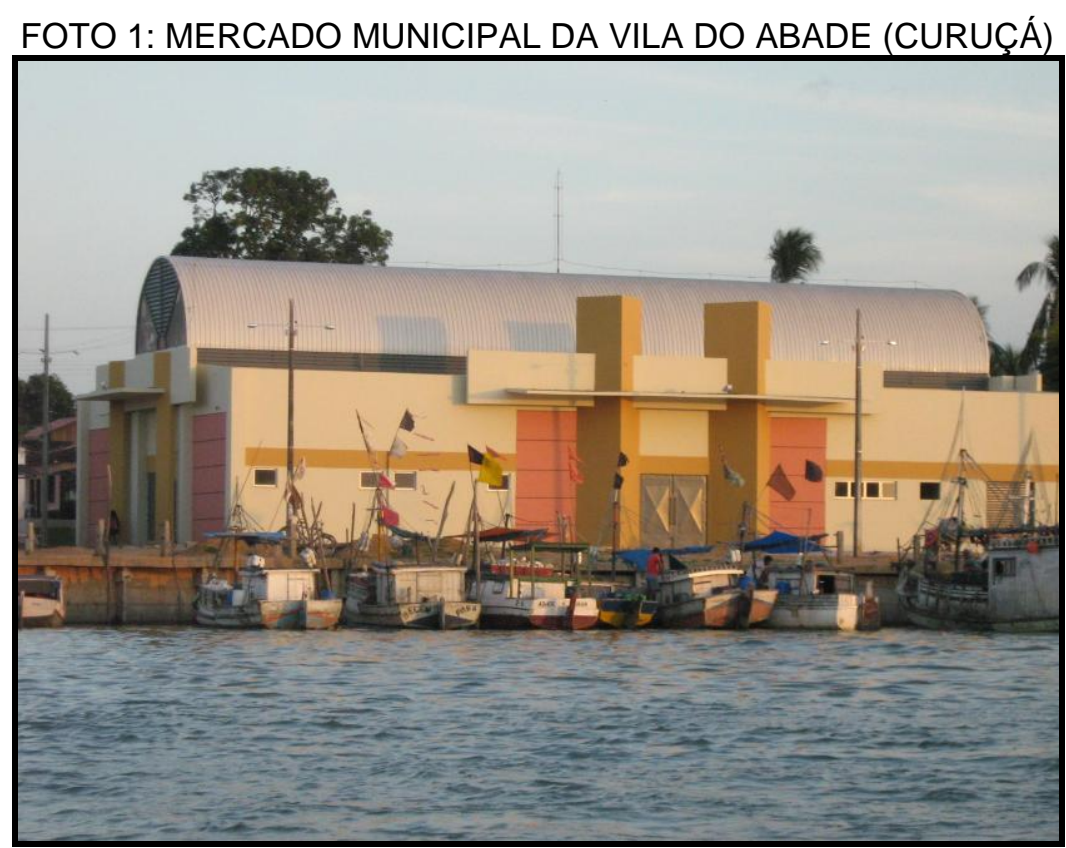

Fonte: Charles B. Gemaque Souza

Em 1997 começou a mobilização comunitária em Curuçá que culminou com o decreto de 13 de dezembro de 2002 que criou a Reserva extrativista marinha de Mãe Grande. Essa denominação, escolhida pelos próprios atores envolvidos, tem o intuito de passar a idéia de que todos vieram de um mesmo lugar, trazendo alguma coisa do inicio: a mãe (Gaia). Existem cerca de 3000 famílias nas 52 comunidades da Resex, calcula-se que o numero de extrativistas e pescadores sejam entorno de 6000 . 


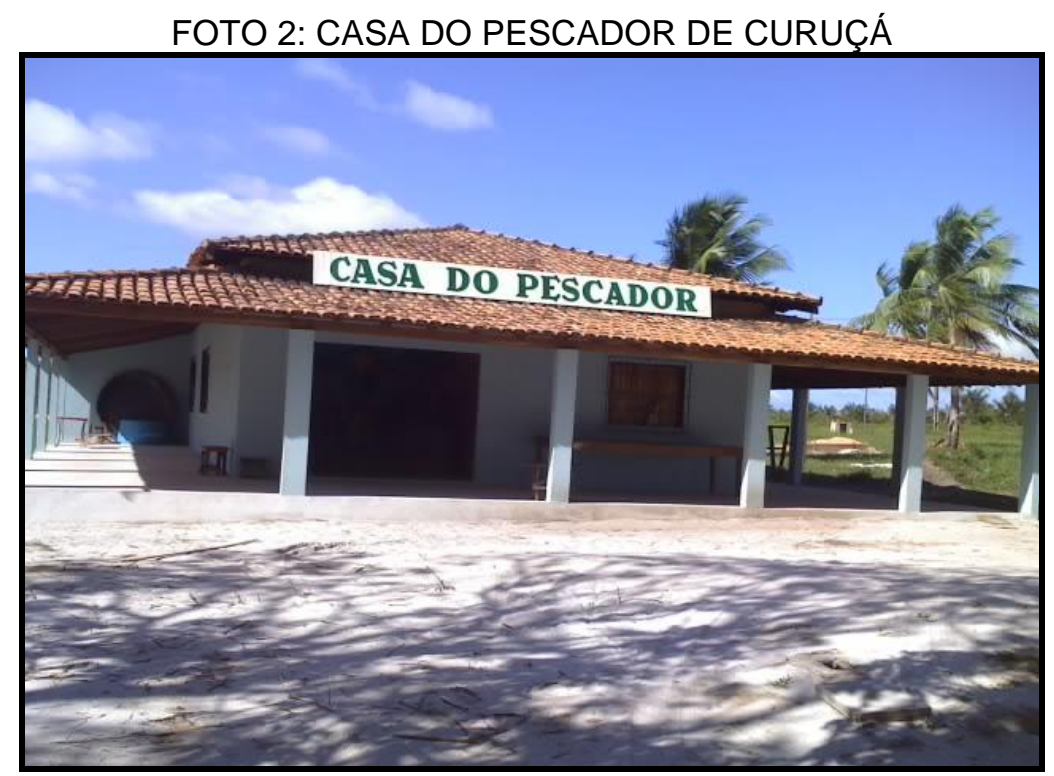

Fonte: Charles B. Gemaque Souza

A Associação dos Usuários da Reserva Extrativista Mãe Grande de Curuçá (AUREMAG) é gerenciado a partir de um conselho deliberativo, coordenado pelo IBAMA. É ao todo 27 membros, a maioria da sociedade civil, incluindo a prefeitura municipal de Curuçá, associações locais e ONG's. A estratégia de gestão trabalha com comitês comunitários instalados em oito pólos: cidade, Caratateua, Ramos, Candeua, Cutumateua, Boa vista, Nazaré de Mocajuba.

A Reserva extrativista marinha Mãe Grande protege igarapés, restingas, ilhas, furos, rios, praias e os manguezais medindo entorno de 37 062,09 hectares, englobando praticamente todo o estuário do município de Curuçá. Seus recursos naturais encontram-se diretamente ligados a atividade pesqueira (mariscagem, pesca artesanal) e ao extrativismo vegetal (coleta tradicional de produtos florestais), conquanto com uma possibilidade concreta de abrigar um grande porto de escoamento nacional (FIGUEIREDO, 2007: 38).

Nesse sentido, a idéia de desenvolvimento para a região ainda é um conceito diretamente amarrado ao sentido de progresso técnico e cientifico ocidental da racionalidade instrumental, em contraposição qualquer orientação diferenciada (emocional e/ou tradicional) é denominada de irracional. Neste sentido, há uma secularização dos atos individuais e competitivos, bem como uma desvinculação em relação às determinadas estruturas sociais consideradas não modernas. 
Diante disso, a discussão em torno da construção de um grande porto off-shore espadarte, na praia da Romana, um dos pontos turísticos e pesqueiros mais conhecidos do município, cria novas expectativas de modernização, desprezando os possíveis impactos negativos na estrutura e mobilização na Resex. Mais recentemente, outro projeto, agora da empresa mineradora MMX propôs a construção de uma estação flutuante de transbordo, na mesma área do porto espadarte, com o mesmo discurso de um "futuro melhor".

Nestes termos, o contexto sócio-político atual na cidade de Curuçá é conturbado diante da perspectiva de construção de grandes empreendimentos aparentemente antagônicos aos interesses das comunidades pesqueiras da Resex Mãe Grande. A interação entre os gestores municipais e os lideres dessas comunidades é caracterizada como sendo de "afastamento", muito pelo descrédito e/ou pela falta de interesse pelo processo de construção de uma Resex no município.

Contudo, a situação se alterou quando iniciou o processo de liberação de verbas do INCRA para o Projeto de Assentamento Extrativista de cerca de 1200 membros das comunidades locais, porém tal reaproximação da administração municipal busca, segundo relatos obtidos nas comunidades locais, o controle e não a parceria. Outro problema citado é o assistencialismo, o que não permite uma mudança na construção da cidadania nas comunidades, isto comprovado pela ausência de representação legal dos moradores da Resex na câmara municipal.

Assim, a realidade de Curuçá possui uma reserva extrativista marinha povoada por dezenas de comunidades tradicionais de pescadores artesanais, dotada de um centro urbano com mais de 15 mil habitantes apresentando um crescimento econômico e populacional, com recursos naturais em interação direta com a ação da pesqueira tradicional e ainda lidando com a possibilidade concreta de abrigar, num futuro próximo, um grande empreendimento econômico na região. 


\section{CONSIDERAÇÕES FINAIS}

A idéia de sustentabilidade das Resex's passa por duas dimensões principais: a ambiental e a socioeconômica. Nestes termos, precisa atender tanto as necessidades de conservação dos recursos naturais, bem como a viabilização comercial e produtiva das atividades desenvolvidas pelas comunidades locais.

Para isso, a elaboração de um plano de manejo para Resex marinha Mãe Grande é um instrumento fundamental. Neste contexto, questões como a chegada de novas atividades pesqueiras, com a alocação de currais no meio do rio, de cercas e da pesca de arraste, precisam ser controladas sob pena de haver uma queda no estoque natural. Outro ponto é o desmatamento da mata ciliar para a construção desses currais, que estão causando erosão e assoreamento nas áreas de mangue.

Entretanto, a defesa de territórios marinhos por parte de pescadores artesanais não é uma tarefa fácil, primeiro pela dificuldade de apropriação dos espaços marítimos fora do contexto social dos envolvidos. Em outras palavras, existem distintas formas culturais e econômicas de se relacionar com o rio, o que dificulta qualquer tentativa de universalização dessa interação.

Por outro lado, a cultura ribeirinha em Curuçá não ajuda neste sentido, já que os pescadores estão acostumados a desmatar a cabeceira dos igarapés e dos rios. Os pequenos agricultores, por exemplo, buscam a proximidade dos igarapés para facilitar a irrigação do plantio, no entanto com as queimadas e o desmatamento causam a lixiviação e o assoreamento das beiradas. Em relação à pesca, o problema não se resume aos pescadores locais, mas a pescaria de arraste industrial.

Neste contexto, a delimitação de territórios exclusivos para pescadores tradicionais encontra dificuldade de legitimação entre os outros grupos. Para Chamy (2008) as Reservas extrativistas marinhas ao determinar áreas até então consideradas de livre acesso transformando-as em espaços onde os recursos são explorados de forma comunitária por pescadores artesanais organizados, reconhece o direito consuetudinário desses grupos sobre territórios marinhos e exclui os não comunitários do aproveitamento dos recursos do mar nas áreas delimitadas. 
No caso da Resex Mãe Grande a delimitação dos territórios produtivos por pescadores artesanais se dá pela associação da ocupação secular desses espaços com o conhecimento empírico que as diversas comunidades locais possuem sobre o ambiente ribeirinho, um espaço dinâmico responsável pela existência de relações históricas e simbólicas específicas do homem com a natureza.

O problema é que o conhecimento que estas comunidades possuem a respeito de seus domínios tradicionais corre o risco de se perder devido à modernização dos espaços ditada pelos avanços da economia urbano/industrial e globalização cultural. Uma preocupação sempre presente nestas comunidades é o desinteresse das novas gerações em relação às atividades consideradas tradicionais e até mesmo a desvalorização da identidade dessas comunidades.

Outra questão que preocupa é a questão de uma possível especulação do uso do solo, de acordo com o relato de alguns deles existem dentro das comunidades alguns pescadores que venderam terrenos dentro da Resex, para servir de casa de veraneio, o que é explicitamente proibido em terras devolutas. A preocupação é que haja uma continua expropriação dos moradores originários no futuro, como aconteceu em outras localidades amazônicas.

Percebe-se que as atividades extrativistas nas comunidades da Resex Mãe Grande mantêm regras tradicionais estabelecidas no convívio com a natureza durante anos. A interação com a modernidade em termos produtivos ainda é incipiente, criando uma lógica capitalista inacabada para os padrões atuais. As relações de trabalho são de base familiar, onde as mulheres têm um papel de destaque, inclusive com comunidades de mulheres marisqueiras.

Evidentemente, é preciso conciliar tais praticas sustentáveis com a economia de mercado, o que não significa entrar em conflito com o modo de vida dos pescadores. A inovação depende de um progresso nas técnicas de produção e no escoamento, no entanto ao contrario do que aponta Homma (1989), neste caso o incremento pode ser fruto de um processo tácito e cumulativo de aprendizado fortalecendo o arranjo produtivo dentro das próprias Resex como visto no caso Resex Chico Mendes (MACIEL, 2003) 
Para Chamy (2008) para que a gestão dos recursos naturais pesqueiros tornese sustentáveis em todas suas dimensões é necessário um reconhecimento e uma incorporação dos saberes tradicionais nas estratégias de desenvolvimento local. Logo, exige um posicionamento diferente daquele tomado até agora pela maioria da população do município de Curuçá.

O contexto de Curuçá indica que há um grande dilema entre uma concepção de base extrativista voltada para conservação ambiental e equidade social e a perspectiva geral de um desenvolvimento econômico significativo através da criação de empreendimentos econômicos grandiosos. Nesta direção, é preciso atentar-se para a diversidade de interesses envolvidos e como tais empreendimentos podem repercutir não apenas na Reserva extrativista marinha Mãe Grande, como na sociedade local.

Dentro disso vários pontos podem ser destacados, tanto questões internas da Resex como o fortalecimento das associações comunitárias e amadurecimento político dos moradores, os grupos políticos dentro das comunidades, os conflitos entre as gerações, a questão dos mecanismos de preservação do ambiente e da identidade cultural, a preocupação com a viabilidade econômica da Resex e sua dependência institucional. Por outro lado, a relação conflituosa entre o poder municipal e os "lideres" da Resex mostra que existem ressentimentos mútuos que acabam prejudicando as comunidades locais.

Conforme infere Galdino (2007) existe uma dificuldade de ajustar a racionalidade instrumental com modelos mais tradicionais de determinadas comunidades pesqueiras onde as relações capitalistas não estão plenamente consolidadas. Tal realidade expressa a heterogeneidade que envolve qualquer discussão sobre o município de Curuçá, o que significa que a analise teórica precisa de aprofundamento que ultrapassa as barreiras disciplinares. Diante disso, esta é apenas uma contribuição inicial para que dentro de uma concepção de desenvolvimento diferenciado e interdisciplinar buscar alternativas sustentáveis para o município. 


\section{BIBLIOGRAFIA}

ALLEGRETTI, Maria. Reservas extrativistas: parâmetros para uma política de desenvolvimento sustentável na Amazônia. In: ARENDT, R. O destino da floresta. Relume Dumara: Rio de Janeiro, 1994a. p.17-48.

ALLEGRETTI, Maria. Políticas para o uso dos recursos naturais renováveis: A região amazônica e as atividades extrativistas. In: SACHS, Ignacy et al. Extrativismo na Amazônia brasileira: perspectiva sobre o desenvolvimento regional. Compêndio MAB 18-UNESCO, Paris, 1994b.p.14-34.

AMIN, M. M. O extrativismo como fator de empobrecimento da economia do Pará. In: XIMENES, Tereza (org.). Perspectivas do desenvolvimento sustentável (uma contribuição para a Amazônia 21). Belém: Universidade Federal do Pará. Núcleo de Altos Estudos Amazônicos; Associação de Universidades da Amazônia, 1997. p. 177-209.

BUNKER, Stephen G. Underveloping the Amazon: Extraction, unequal exchange and failure of the modern state. Universidad de Ilinois, 1985.

CAVALCANTI, Omifran P. A polêmica em torno do conceito de Reserva Extrativista enquanto atividade econômica sustentável. Monografia de Economia. UFA, Rio Branco, 1993.

CHAMY, Paula. Reservas extrativistas marinhas: um estudo sobre posse tradicional e sustentabilidade. Encontro nacional da ANPPAS, Brasília, 2008.

FERREIRA, Paulo Henrique dos Santos. Fragmentos históricos de Curuçá. Castanhal: Graf - set, vol. 2, 2005.

FIGUEIREDO, Elida Moura. Uma estrada na reserva: Impactos sócio-ambientais da PA 136 em Mãe Grande, Curuçá (PA). Dissertação em Ciências Ambientais. UFPA/EMBRAPA/ Museu Emilio Goeldi, Belém, 2007.

GALDINO, Ana Paula P. Estudo sobre o potencial agrícola do município de CuruçáPA. Instituto Peabiru, 2007.

HOMMA, A.K.O. A (ir)racionalidade do extrativismo vegetal como paradigma de desenvolvimento agrícola para a Amazônia. In: COSTA, J.M. Amazônia: desenvolvimento ou retrocesso. Belém/Cejup, 1992. p. 163-207.

HOMMA, A.K.O. Reservas extrativistas: uma opção de desenvolvimento viável para a Amazônia? Para desenvolvimento 25:34-48, 1989.

MACIEL, Raimundo Claudio G. Ilhas de alta produtividade: inovação essencial para a manutenção dos seringueiros nas reservas Extrativistas. Dissertação de mestrado. Instituto de Economia/UNICAMP, Campinas, 2003.

MARINHO, José Antonio Magalhães. Desenvolvimento do extrativismo do Açaí e mudanças na socioeconômica de uma população marajoara. Dissertação de mestrado. NAEA/UFPA, Belém, 2005. 
REGO, J.F. Amazônia: do extrativismo ao neo-extrativismo. Poema tropico, Belém 4: 34-37, 1999.

SIMONIAN, Ligia T.L.; GLASER, M. Extractive Reserves and the Question of Sustainability: Recent Experiences in North of Brazil. German-Brazilian Workshop on Neotropical Ecosystems - Achievements and Prospects of Cooperative Research Hamburg, September 3-8, 2000

TORRES, Vera Lucia Scaramuzzini. Envelhecimento e pesca: redes sociais no estuário amazônico. Belém, Cejup, 2004

(Recebido em junho/2009. Aceito em Janeiro/2010) 